\title{
VEHICLE AND LABOR REQUIREMENTS FOR YARD WASTE COLLECTION
}

\author{
Jess W. Everett and Shiv Shahi
}

The University of Oklahoma, Norman, Oklahoma, U.S.A.

(Received 1 September 1995, accepted in revised form 13 November 1996)

\begin{abstract}
Curbside collection of yard waste material is costly because the amounts collected per residence are small compared to the total waste stream and time is wasted driving by non-setting-out residences. In this paper, mathematical models are presented capable of estimating route time based on the distribution and amount of materials collected, and route and collection method characteristics. A method is presented that uses route time, set-out rate, and average set-out amount to estimate vehicle and labor requirements for compost curbside collection programs. The effect of collection practice on vehicle and labor needs is also explored. (C) 1997 ISWA
\end{abstract}

Key Words - Yard waste collection, vehicle and labor requirements, modeling.

\section{Introduction}

Yard waste, i.e. grass, leaves, and brush, is the second most prevalent material in municipal solid waste (MSW) in the United States, following paper products. Many communities have implemented, or will implement in the near future, centralized composting facilities for yard waste, in many cases using curbside collection.

Collection cost plays a significant role in the curbside collection of yard waste. First, the amount of material collected per residence is small compared to the total waste stream. Second, considerable time can be wasted in driving by non-participating residences. Thus, route time, i.e. the total time spent collecting yard waste on a given route, may vary considerably depending on the amount, number, and distribution of residences setting out yard waste. Finally, collection may be further complicated if it involves additional on-route tasks, such as debagging.

The goal of this paper is to use a recently developed route time estimation method to estimate route time and vehicle and labor needs for a range of set-out rates and collection practices. The objectives are:

(1) To present a method for estimating vehicle and labor requirements for the curbside collection of municipal solid waste.

(2) To present methods capable of estimating the time required for curbside collection of variable amounts of yard waste, based on the distribution and amount of material collected, collection method, and route characteristics.

(3) To examine the effect on vehicle and labor requirements of changes in set-out rate and collection practice.

(4) To present conclusions and suggest future research needs. 


\section{MSW collection}

A deterministic approach to estimating MSW collection costs, adopted from Tchobanoglous et al. (1993), is presented below. The method can be used to estimate the available time per route, the required vehicle capacity, and the number of routes and vehicles required. From this information capital, operating, maintenance and labor costs can be estimated. Given that the objective of an activity is to collect materials from residences, the time available for each route for a given vehicle is:

$$
P_{\mathrm{scs}}=\frac{H(1-W)-\left(t_{1}+t_{2}\right)}{N_{\mathrm{d}}}-(s+h)
$$

where: $\boldsymbol{P}_{\text {scs }}=$ time spent collecting materials from residences on each route, from the first residence to the last, $\mathrm{h}$ route ${ }^{-1} ; H=$ time vehicle is on the road each working day, $\mathrm{h}$ working day ${ }^{-1} ; W=$ off-route time factor, consisting of the fraction of the day spent in non-productive activities such as breaks; $t_{1}=$ time spent at beginning of day driving vehicle from dispatch area to first residence, $\mathrm{h}$ working day ${ }^{-1} ; t_{2}=$ time spent at end of day driving vehicle from last residence to dispatch point, h working day ${ }^{-1} ; N_{\mathrm{d}}=$ number of routes each vehicle can complete in a working day, routes working day ${ }^{-1} ; s=$ time spent at the unloading site per route, $h$ route $^{-1}$; and $h=$ round trip haul time from end of typical route to unloading site and back to beginning of next route, h route ${ }^{-1}$. A route consists of the path through a neighborhood taken while loading a collection vehicle. The maximum number of residences per route is:

$$
N_{\mathrm{p}}=\frac{60 P_{\mathrm{scs}} n}{t_{\mathrm{p}}}
$$

where: $N_{\mathrm{p}}=$ number of residences per route, residences route ${ }^{-1} ; n=$ number of collectors riding on the vehicle, collectors; and $t_{\mathrm{p}}=$ collector-time per residence (a function of setout rate and distribution, the number of collectors, the average number of containers set out, the equipment used, the average distance between pick-up points, and the setout point, e.g. curbside or backyard), collector-minutes residence ${ }^{-1}$. The volume of material set out at each setting-out residence is:

$$
V_{\mathrm{R}}=\frac{M P_{\mathrm{R}} C_{\mathrm{p}}}{S W}
$$

where: $V_{\mathrm{R}}=$ volume of waste collected at each residence during each collection period, $\mathrm{yd}^{3}$ residence $^{-1} ; M=$ waste set out per person per day, $1 \mathrm{~b}$ person ${ }^{-1} \mathrm{~d}^{-1} ; P_{\mathrm{R}}=$ persons per residence, persons residence ${ }^{-1} ; C_{\mathrm{p}}=$ the time between collections, days; and $S W=$ density of waste as set out, $\mathrm{lb} \mathrm{yd}^{-3}$. Therefore, the required volume of the collection vehicle is:

$$
v=\frac{V_{\mathrm{R}} N_{\mathrm{p}} S O R}{r}
$$

where: $v=$ required volume of vehicle, $\mathrm{yd}^{3}$ route $^{-1} ; S O R=$ set-out rate, i.e. the fraction

${ }^{1} 1 \mathrm{lb}=0.454 \mathrm{~kg} ; 1 \mathrm{yd}=0.91 \mathrm{~m} ; 1 \mathrm{ft}=0.30 \mathrm{~m}$. 
of homes at which materials are set out; and $r=$ compaction ratio. The number of routes that must be driven during each collection period is:

$$
R_{\mathrm{cp}}=\frac{N O R}{N_{\mathrm{p}}}
$$

where: $R_{\mathrm{cp}}=$ the number of routes that must be driven each collection period, routes; and $N O R=$ the number of residences that must be served each collection period, residences. The number of vehicles required is:

$$
N O V=\frac{R_{\mathrm{cp}}}{N_{\mathrm{d}} C_{\mathrm{p}}^{\mathrm{W}}}
$$

where: $N O V=$ the number of vehicles required to operate the collection program, unitless; and $C_{\mathrm{p}}^{\mathrm{W}}=$ the number of working days in each collection period, working days. The labor requirements are:

$$
L R=\frac{n\left\{R_{\mathrm{cp}} P_{\mathrm{scs}}+R_{\mathrm{cp}}^{\dagger \dagger}(s+h)+C_{\mathrm{p}}^{\mathrm{W}}\left(t_{1}+t_{2}\right)\right\} 7(\text { days } / \text { week })}{(1-W) H C_{\mathrm{p}}}
$$

where: $L R=$ the labor requirements, collector-workdays week ${ }^{-1}$; and $R_{\mathrm{cp}}^{1 \dagger}=$ the integer number of routes in a collection period, i.e. the smallest integer larger than $R_{\mathrm{cp}}$, routes.

For yard waste collection, $t_{\mathrm{p}}$ is a function of collection method, route characteristics, and set-out rate. Set-out rate varies from collection day to collection day, thus $t_{\mathrm{p}}$ also varies, resulting in variation in $v, N O V$, and $L R$. In subsequent sections methods for estimating $t_{\mathrm{p}}$ for the curbside collection of yard waste material are presented. A hypothetical example that illustrates the use of equations [1] to [7] for yard waste collection is also presented. Finally, the effect of various collection parameters on vehicle and labor requirements are explored.

\section{Yard waste curbside collection model}

A route time estimation model has been developed by the authors, and is presented in detail in Everett and Shahi $(1996 a, b)$. The model works by simulating the activity of a collection vehicle completing a known route with known distribution and amounts of set outs. The required input information includes collection method characteristics, collection route characteristics, and the set-out distribution and amount. Collection method characteristics include relationships between travel time and travel distance and collection time and amount of yard waste loaded. Collection route characteristics include the distances between all adjacent potential stops, including residences, stop signs, and traffic lights, and the average time spent at stop signs and traffic lights. The set-out distribution describes which residences do and do not set out yard waste on a given collection day. The set-out amount describes how much material is set out at each setting-out residence.

The model works by computing the distance from the current vehicle stop to the next stop point. A "stop" is considered to be any setting-out residence, stop sign, or traffic light. Traveling from one stop to the next is called a "run". The travel time between two stops is computed based on the distance traveled and characteristics of 
the collection vehicle. The next stop then becomes the new current stop. The time spent at the new current stop is computed based on the amount of material set out (collection time) or, in the case of stop signs and traffic lights, an average wait time is computed. A new stop point is identified and the process repeats itself. Travel, collection, and wait times are summed over the entire route. The model does not compute unproductive time such as breaks or time spent writing instructions to residents failing to meet program requirements.

The model uses mathematical equations to compute travel time between each pair of stops, collection time for yard waste units at each setting-out residence, and wait times at stop signs and traffic lights. Model parameters have been developed for a yard waste collection program in Norman, Oklahoma (Everett \& Shahi 1996a,b) and a curbside recycling program in The City of The Village, Oklahoma (Riley \& Everett 1995). In this paper, the yard waste collection model is described and used.

In Norman, Oklahoma, yard waste, i.e. grass, leaves, and brush with stems under 2 inches $(5 \mathrm{~cm})$ in diameter, is set out at the curbs in bags, cans or bundles once a week. Tree branches and shrubs are tied in a bundle or placed in cans. Bags, cans or bundles, called "units", are collected in 20-cubic yard compaction vehicles by three-person crews, including a driver who rarely engages in loading activity. Materials are debagged as necessary during the manual loading process.

The time spent traveling over a route is estimated as:

$$
T T T=\sum_{i=1}^{N}\left(\frac{D_{\mathrm{i}}}{L\left(1-\mathrm{e}^{-\mathrm{k} \times D}\right) C}\right)
$$

where: $T T T=$ the total travel time over a given route, $\mathrm{s} ; D_{1}=$ the distance traveled over the $i$ th run on the route, $\mathrm{ft} ; N=$ the number of runs on the route; $L=$ maximum achievable speed of the collection vehicle, miles per hour; $\mathrm{k}=$ an empirical coefficient, $\mathrm{ft}^{-1}$; and $C=$ conversion factor, 1.467 for English units, 0.278 for metric units. The parameters $L$ and $\mathrm{k}$ have been estimated for a yard waste collection program in Norman, Oklahoma. The values were determined to be 10.7 miles per $\mathrm{h}$ and $0.01 \mathrm{ft}^{-1}$, respectively.

The collection time over a given route is estimated as:

$$
T C T=S O R \times N O R(a+b \times A U)
$$

where: $T C T=$ total collection time over entire route, $\mathrm{s} ; S O R=$ setting-out rate as a fraction; NOR is the number of residences on the route, $a$ and $b$ are empirical coefficients, and $A U=$ average number of units collected at setting-out residences. The coefficients $a$ and $b$ were estimated to be $9.23 \mathrm{~s}$ and $11.6 \mathrm{~s}$ per unit for the Norman, Oklahoma, collection program.

The equation for estimating total wait time is:

$$
T W T=\left(M_{\mathrm{ss}} \times N_{\mathrm{ss}}\right)+\left(M_{\mathrm{t} 1} \times N_{\mathrm{tl}}\right)
$$

where: $T W T=$ total time spent at stop signs and traffic lights over the route, $\mathrm{s} ; M_{\mathrm{ss}}=$ mean time spent at stop sign, s; $N_{\mathrm{ss}}=$ number of stop signs; $M_{\mathrm{tl}}=$ mean time spent at traffic lights, $\mathrm{s}$; and $N_{\mathrm{tl}}=$ number of traffic lights. The route has 16 stop signs and 7 traffic lights, with average wait times of 7.1 and $11.9 \mathrm{~s}$, respectively. 
The model is capable of estimating route time, i.e. the sum of the total travel, collection, and wait times for the collection of yard waste from the residential neighborhood. The model was executed using a computer program written in FORTRAN and used to estimate route time for six observed collection days. The model estimated route time for the six observed collection days to within 3.6\% (Everett \& Shahi 1996a).

The high accuracy of the model concerning the observed collection route does not mean that it can be directly applied to other collection methods or collection routes. Such application may require parameter re-estimation for the total travel, collection, and wait time equations. The model may not even be applicable to the same route for collection days other than the six observed. For example, the weather, the driver or the season might effect the required parameters. However, the model accurately predicted route time for the six observed collection days, which varied according to weather and driver. Additional research has already focused on some of these issues (see, for example, Riley \& Everett 1995).

The observed set-out rates $(S O R)$ for the six collection runs only varied from 23.5 to $30.2 \%$. However, it may be useful to estimate route time for other SORs. For example, if a promotion program is to be undertaken that is expected to raise participation levels, and thus set-out rates, it will be desirable to estimate the resulting route times and vehicle and labor needs. Alternatively, a program operator may wish to identify the low $S O R$ at which collection becomes prohibitively expensive.

The computer program used to estimate route time at any $S O R$ is similar to the one described above, except that, for each run of the simulation program, set-out status is assigned randomly in such a way that a given set-out rate is obtained. By running the model many times at each set-out rate, the mean and standard deviation of route time $(R T)$ can be determined. Estimated mean route times for the observed yard waste collection route are shown in Fig. 1(a). Estimated mean route times divided by the number of units collected $(R T U)$ are shown in Fig. 1(b). The curve shown in Fig. 1(b) increases rapidly as $S O R$ approaches zero, indicating that collection becomes increasingly impractical.

The accuracy of such a model, however, is not assured over the entire $S O R$ range. For example, it may not be reasonable to assume that the equations derived from collection days during which $S O R$ ranged from 23 to $30 \%$ can be applied to SORs from 0 to $100 \%$. For example, though the stated speed limit on the route is 25 miles per hour (mph), the maximum speed used by the model, based on observation, is only $10.7 \mathrm{mph}\left(17.1 \mathrm{~km} \mathrm{~h}^{-1}\right)$. The collection vehicle was observed to rarely reach the speed limit; perhaps the driver was looking for the next setting-out residence, ready for the next stop. However, if $S O R$ is routinely very low, the driver might expect to drive long distances between stops and might attempt to attain higher speeds. Alternatively, very high $S O R$ s might result in the modification of collection procedures. For example, not once during the six observed collection days was the vehicle stopped to collect two residences at once. High set-out rates might cause this policy to be reconsidered. It is also difficult to identify a relationship between $S O R$ and set-out amount. Unfortunately, it is difficult to test the simulation model by observing high or low set-out rates on actual collection routes, because they occur infrequently.

Inspection of the estimated route time $95 \%$ confidence interval showed that it was small above approximately $5 \%$ SOR (see Everett \& Shahi 1996b). Very few, if any, yard waste curbside collection programs will have $S O R$ s below or even near $5 \%$. Thus, for the parameters used and for typical SORs, the effect of set-out distribution on $R T$ appears to be unimportant. 

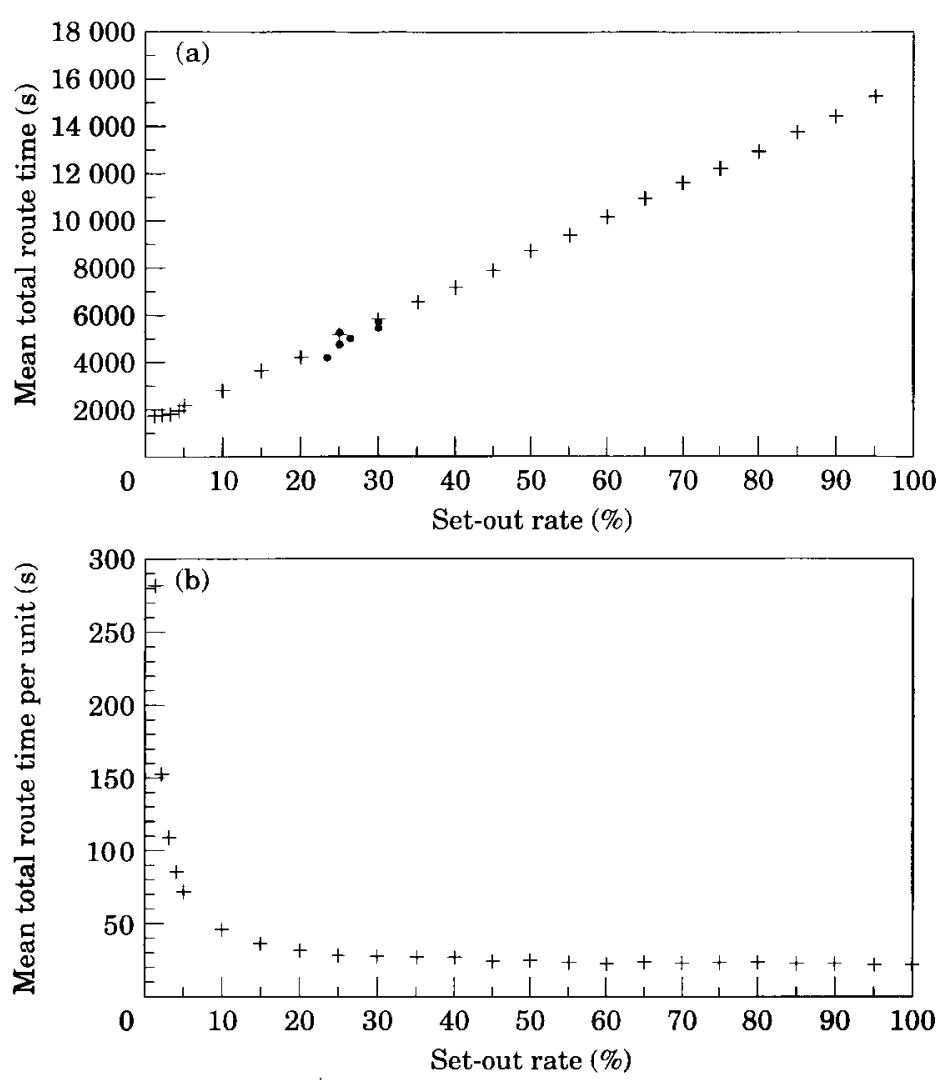

Fig. 1. Observed neighborhood simulation: (a) mean route time vs set-out rate; (b) mean route time per unit vs set-out rate. $(+)$, mean simulated route time; $(\mathbf{O})$, observed route time.

\section{Simple estimation procedure}

The simulation analyses performed for the observed route indicated that even at low set-out rates, route time is relatively insensitive to set-out distribution. Therefore, a simple one-step estimation procedure, which uses the average run distance, was developed and used to predict travel and collection times over a wide range of set-out rates. The simple estimation procedure differs from the simulation method presented above only in the calculation of TTT. The total travel time is estimated by assuming that all stops are distributed uniformly. Thus, the average distance traveled between stops is:

$$
A D B S=\frac{R D}{\left(S O R \times N O R+N_{\mathrm{ss}}+N_{\mathrm{t} 1}+1\right)}
$$

where: $A D B S=$ the average distance between stops, $\mathrm{ft}$; and $R D=$ route length, $\mathrm{ft}$. The total travel time over the route is the route distance divided by the average vehicle speed, i.e.:

$$
T T T_{\mathrm{sep}}=\frac{R D}{L\left[1-\mathrm{e}^{(-\mathbf{k} \times A D B S)}\right] C}
$$


where: $T T T_{\text {sep }}=$ the total travel time estimated by the simple estimation procedure, $\mathrm{s}$. The route time $\left(R T_{\mathrm{sep}}\right)$ is computed by adding total travel, collection, and wait time, i.e. equations [9], [10], and [12].

A comparison of route time estimated by the simulation program and the simple estimation procedure indicated that the simple estimation procedure accurately predicts the simulation program mean $R T$ and $R T U$ for $S O R$ above $30 \%$ SOR (see Everett \& Shahi $1996 b$ ). At lower values the simple estimation procedure overestimates mean $R T$ and $R T U$, though values are within $8 \%$ of the simulation model estimate down to $15 \%$ $S O R$. Because few programs will have $S O R$ s below $15 \%$, it can be inferred that - for the parameters used-RT and $R T U$ can be estimated using a simple procedure that can be carried out by hand or with a spreadsheet, avoiding the complication of running the FORTRAN simulation program.

\section{Calculation of vehicle and labor requirements}

The simulation model or the simple estimation procedure can be used to estimate collector-minutes per residence, $t_{\mathrm{p}}$. The relationship is:

$$
t_{\mathrm{p}}=\frac{n R T_{\text {sep }}}{60 N O R}
$$

where all the variables have been defined previously. This can be combined with equations [1] to [7] to estimate the required vehicle volume, number of vehicles required, and labor requirements for a given collection program and service area.

In order to better illustrate the estimation of vehicle and labor requirements, an example is presented for a hypothetical collection program. This hypothetical example is also used in the next section, to investigate the effect of changes in collection practice on vehicle and labor needs. A hypothetical example is used because each collection method and community is different. By presenting a hypothetical example, it is possible to demonstrate the method, and present and discuss typical results.

The pertinent values are presented in Table 1 . The parameter values used are reasonable, and in the set-out range of 20 to $30 \%$ results should also be reasonable. The value of the exercise lies in estimating equipment and labor needs to better understand the potential effects of a variety of conditions. The limitation of the exercise is that, the farther the set-out rate is from the 20 to $30 \%$ range, one is less certain of the reasonableness of the results.

Several assumptions are made. First, a single set of parameters for the travel, collection, and wait equations is assumed to apply to all 5000 homes served by the hypothetical collection program. If this was not the case, the residential area could be split into sub-areas, each with its own set of parameters. Second, the parameters are assumed to apply over the entire range of $S O R$ s. Third, the simple estimation procedure is assumed to predict route time adequately for $S O R$ s equal to or above $5 \%$. Finally, the average number of units set out is assumed to remain constant over the entire range of SORs.

The results of the calculations for a range of $S O R$ s are shown in Table 2. The collector-minutes per residence served, $t_{\mathrm{p}}$, increases from 0.38 to $2.15 \mathrm{~min}$ as $S O R$ ranges from 5 to $100 \%$. It is important to note that residences are served by the collection vehicle whether or not materials are set out for collection, i.e. the vehicle passes by 
TABLE 1

Hypothetical example base parameters

\begin{tabular}{|c|c|}
\hline $\begin{array}{l}\text { Variable name } \\
\text { (1) }\end{array}$ & $\begin{array}{l}\text { Value } \\
(2)\end{array}$ \\
\hline$H$ & $8 \mathrm{~h}$ working day ${ }^{-1}$ \\
\hline$W$ & 0.15 \\
\hline$t_{1}$ & $0.3 \mathrm{~h}$ working day ${ }^{-1}$ \\
\hline$t_{2}$ & $0.3 \mathrm{~h}$ working day ${ }^{-1}$ \\
\hline$s$ & 0.2 h route $^{-1}$ \\
\hline$h$ & $0.25 \mathrm{~h}$ route -1 \\
\hline$N_{\mathrm{d}}$ & 2 route/working days \\
\hline$n$ & 3 collectors \\
\hline$M$ & $1.5 \mathrm{lb}$ person day ${ }^{-1}\left(0.23 \mathrm{~kg}\right.$ person $\left.\mathrm{day}^{-1}\right)$ \\
\hline$P_{\mathrm{R}}$ & 3.5 persons residence ${ }^{-1}$ \\
\hline$\widehat{C_{\mathrm{p}}}$ & 7 days \\
\hline$S W$ & $170 \mathrm{lb} / \mathrm{yd}^{3}\left(101 \mathrm{~kg} / \mathrm{m}^{3}\right)$ \\
\hline$r$ & 2.0 \\
\hline$N O R$ & 5000 residences \\
\hline$C_{\mathrm{p}}^{\mathrm{W}}$ & 5 working days \\
\hline$h_{\mathrm{wd}}^{\mathrm{p}}$ & $8 \mathrm{~h}$ working day $^{-1}$ \\
\hline k & $0.01 \mathrm{~s}^{-1}$ \\
\hline $\bar{L}$ & $10.7 \mathrm{mph}\left(17.2 \mathrm{~km} \mathrm{~h}^{-1}\right)$ \\
\hline$A U$ & 2 units \\
\hline$N_{\mathrm{ss}}$ & 300 stop signs \\
\hline$M_{\mathrm{ss}}$ & $7.1 \mathrm{~s}$ \\
\hline$N_{\mathrm{tl}}$ & 100 traffic lights \\
\hline$M_{\mathrm{tI}}$ & $11.9 \mathrm{~s}$ \\
\hline$R D$ & 80 miles $(128.7 \mathrm{~km})$ \\
\hline
\end{tabular}

each residence once per collection period. Thus, $t_{\mathrm{p}}$ is the time spent per residence served, not per residence setting out materials.

The number of residences that can be served per route, $N_{\mathrm{p}}$, decreases as $S O R$ increases, while the required volume of the vehicle increases. At very low $S O R \mathrm{~s}$, the required vehicle volume is small. This indicates that at low SOR it may be advantageous to collect one route per working day, rather than two, i.e. adjust $N_{\mathrm{d}}$. At high $S O R$, the required volume of the vehicle, $v$, is high. For example, if $20 \mathrm{yd}^{3}\left(15 \mathrm{~m}^{3}\right)$ vehicles are to be purchased the calculations shown in Table 2 indicate that a $20 \mathrm{yd}^{3}\left(15 \mathrm{~m}^{3}\right)$ vehicle can only be used up to, approximately, a $40 \% S O R$. If a higher $S O R$ is anticipated, it may be necessary to modify collection procedures.

Referring to Table 2 , the number of routes, $R_{\mathrm{cp}}$, the required number of vehicles, $N O V$, and the labor requirements, $L R$, all increase as $S O R$ increases. $R_{\mathrm{cp}}$ increases from a minimum of 4.0 to a maximum of 22.5 routes. One vehicle will suffice from 5 to $35 \%$ set-out rate, two are required from 40 to 85 , and three are required at 90,95 , and $100 \%$, respectively. If the collection area behaves like the residents of the observed Norman route, SOR might range from 23 to $30 \%$, indicating that one vehicle would suffice. However, if $S O R$ increased significantly, perhaps as a result of promotional activity, an additional vehicle could be required.

A comparison of fractional and integer NOV (Table 2) reveals that vehicles are used inefficiently over large ranges of $S O R$. This indicates that modification of collection method or practice might be advantageous if the expected range of $S O R \mathrm{~s}$ indicates 
Vehicle and labor requirements for yard waste collection

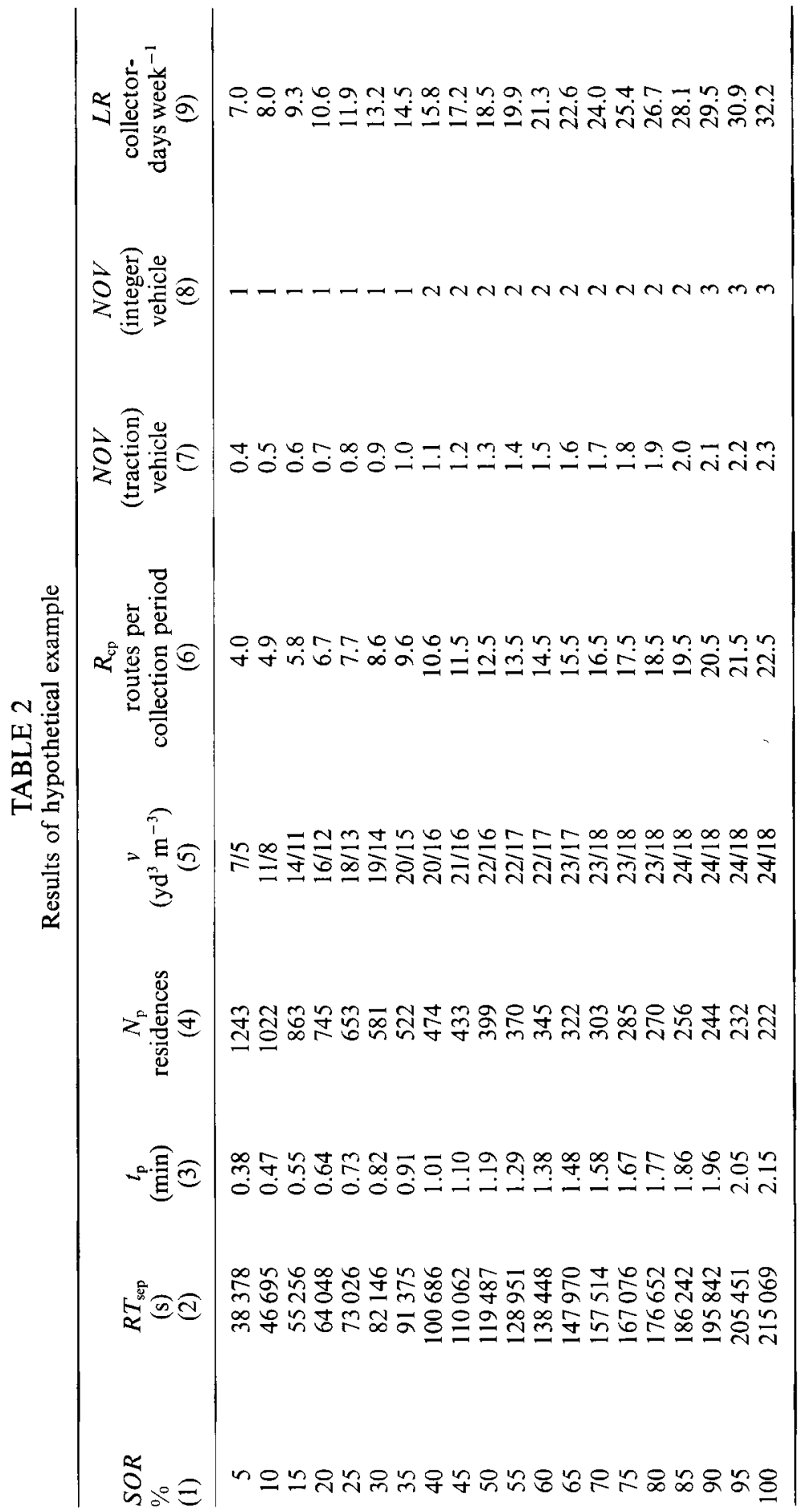




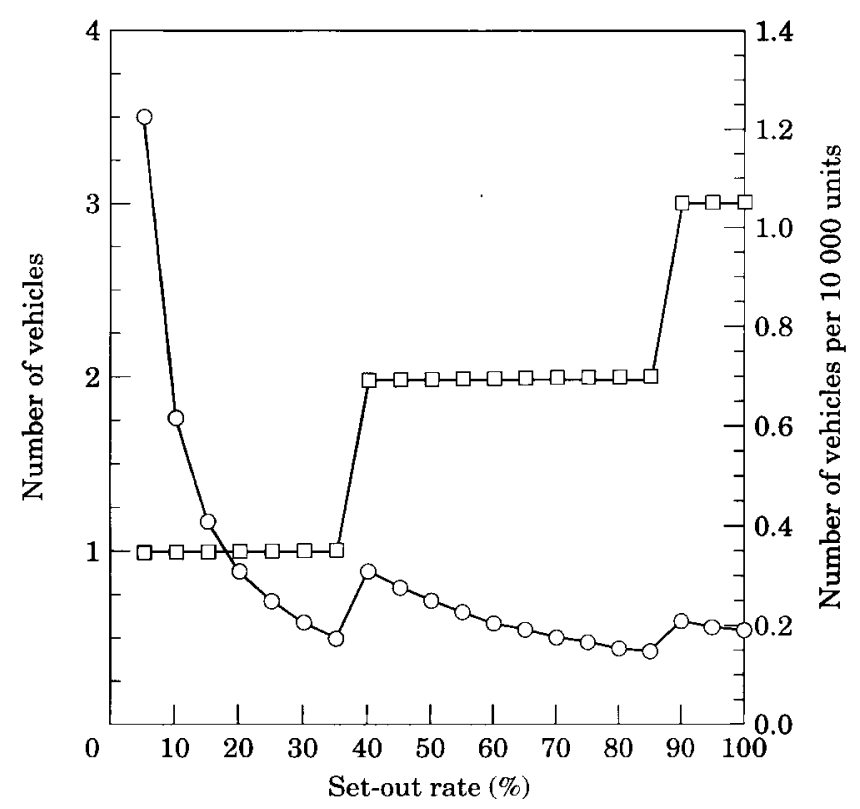

Fig. 2. $N O V$ and $N O V U$ vs. SOR. ( $\square$ ), number of vehicles; (O), number of vehicles per unit.

that the vehicle(s) will be used ineffectively. Table 2 indicates that at $35 \% S O R$, one vehicle can collect all 5000 residences, while at $40 \%$ SOR, two vehicles are required. At 35 and $40 \%$ SOR the fractional $N O V$ is 0.96 and 1.06 , respectively. Thus, the one vehicle required at $30 \%$ SOR is used to $96 \%$ of its capability, while the two vehicles needed at $35 \%$ are only used to $53 \%$ of their capabilities. This can be further illustrated by examining plots of $N O V$ and $N O V$ per unit collected ( $N O V U$ ) vs. $S O R$ (Fig. 2). Though the general trend is for $N O V U$ to decrease as $S O R$ increases, it "jumps" whenever an additional truck is added.

$L R$ increases with $S O R$ from 56 collector-hours week ${ }^{-1}$ to 258 collector-hours week $^{-1}$, at 5 and $100 \%$, respectively, while $L R$ per unit collected ( $L R U)$ decreases from 69 to 16 collector-hours week ${ }^{-1} 10000$ units $^{-1}$ (Fig. 3). As shown in Fig. 3, LR increases at a linear rate with $S O R$, while the slope of the $L R U$ vs. $S O R$ curve approaches zero as SOR increases. This indicates that dramatic labor reduction per unit can be made by increasing low $S O R$ s, while little is realized by increases of already high SORs. Labor requirements will be dependent on collection method and practice.

The term "collection method" refers to the crew size and the actual collection procedure, for example the use of debagging at the collection vehicle vs. the compost facility. Thus, it is used to describe how materials are collected at the residence. Collection method effects the parameters in equations [8], [9], and [10]. The term "collection practice" refers to the parameters in equations [1] to [7], such as $v, r, N_{\mathrm{d}}$, $h_{\mathrm{wd}}$, and $C_{\mathrm{p}}^{\mathrm{w}}$. These parameters describe the framework within which collection occurs. Collection method and practice parameters can be controlled, to a limited extent, by a program operator. An appropriate modification of collection method might involve the use of two-person crews rather than three, reducing the number of homes that can be collected on one route, the required vehicle volume, and labor requirements, but also increasing equipment needs. Modification of collection practice might involve 


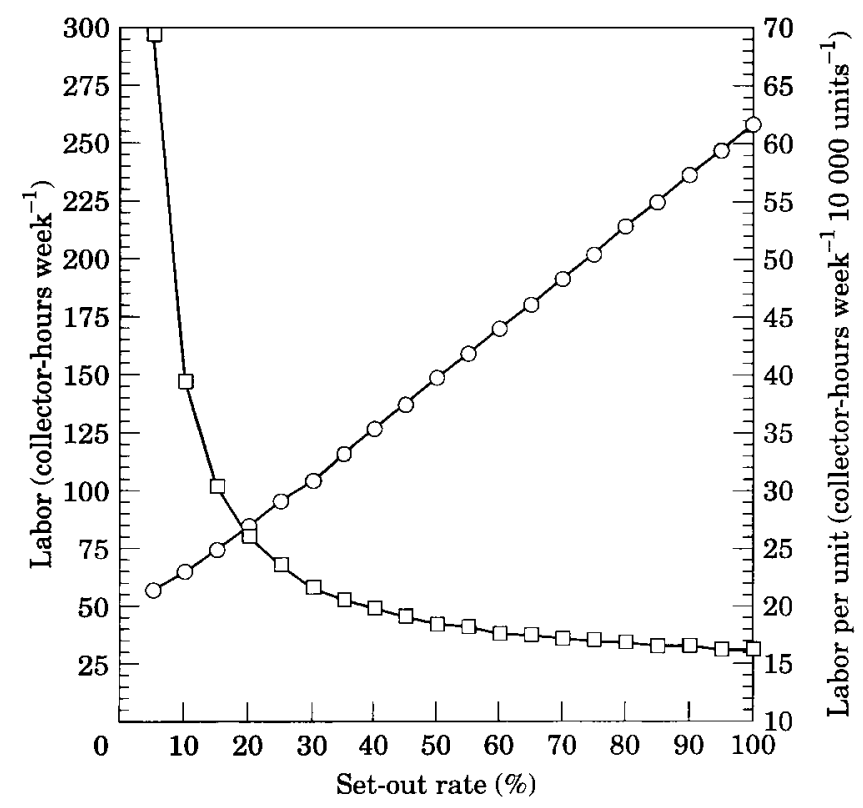

Fig. 3. $L R$ and $L R U$ vs. $S O R$. (O), labor; ( $\square$ ), labor unit.

increasing the compaction ratio, $r$, if technically feasible, or changing the collection frequency.

\section{Modification of collection practice}

The procedures outlined in this paper allow the engineer or planner to explore the effect of modification of collection method or practice on collection efficiency and feasibility. The modification of collection method is explored elsewhere (Everett \& Shahi 1996b). The modification of collection practice is explored in this paper.

The variables which describe the feasibility and efficiency of a collection program are $v$, fractional and integer $N O V, N O V U, L R$ and $L R U$. For example, if $v$ exceeds the capacity of the vehicle, the collection method and practice are not feasible. Relative efficiency can be measured with $N O V U$ and $L R U$. If $N O V U$ and $L R U$ are high, the program is inefficient. The collection practice parameters that are varied here are $r, H$, $N_{\mathrm{d}}$, and $C_{\mathrm{p}}^{\mathrm{w}}$, the compaction ratio, hours per working day, routes per truck per working day, and working days per collection period, respectively.

In order to explore the effect of $r, H, N_{\mathrm{d}}$, and $C_{\mathrm{p}}^{\mathrm{W}}$, each was varied one-by-one, holding all other parameters constant. This is not meant to imply that no more than one parameter can be varied simultaneously; this procedure is followed here to simplify presentation. Using the parameters shown in Table 1 as a base condition, $r$ was allowed to take the values $1.5,2$, and $2.5, H$ was allowed to equal 8 and $10 \mathrm{~h}, N_{\mathrm{d}}$ was allowed to equal 1 and 2 , and $C_{\mathrm{p}}^{\mathrm{W}}$ was allowed to equal 5 and 6 days. 


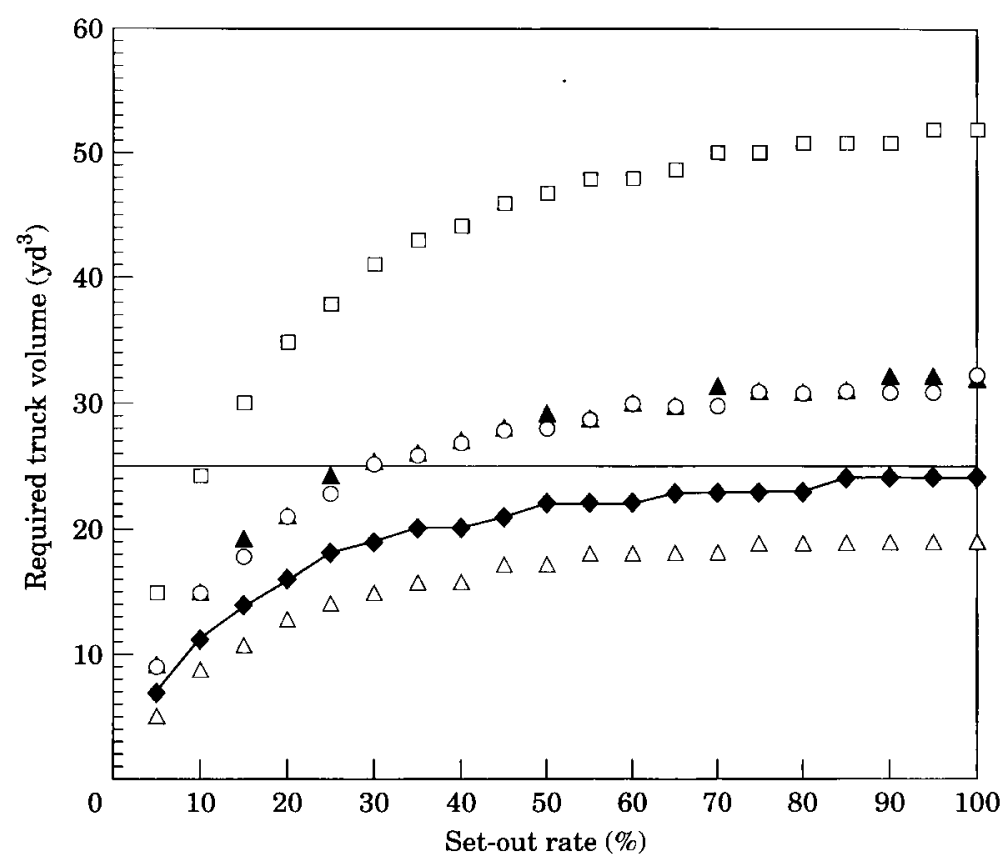

Fig. 4. Effect of collection practice on required truck volume. $(\bullet)$, base condition; $(\bigcirc), H=10 ;(\square), N_{\mathrm{d}}=1$; $(\mathbf{A}), r=1.5 ;(\triangle), r=2.5$.

The effect of these variations on $v$ is shown in Fig. 4. The base condition is shown by the diamonds connected by a line. The line is included only to aid the reader's interpretation of the figure. Note that $C_{\mathrm{p}}^{\mathrm{w}}$ is not shown, as it does not effect $v$. Increasing $r$ from 2 (a base condition) to 2.5 reduces, while decreasing $r$ to 1.5 increases, the required vehicle volume. Reducing $N_{\mathrm{d}}$ or increasing $H$ increases the required vehicle volume. Figure 4 can be used to determine the feasible region for a set of collection practice parameters, a given vehicle volume, and a range of $S O R$ s. For example, if a $25 \mathrm{yd}^{3}$ vehicle is to be used, indicated by the horizontal line, allowing $N_{\mathrm{d}}$ to equal 1 is feasible only if the $S O R$ is expected to be $10 \%$ or less. Alternatively, for this vehicle capacity, the base condition is feasible over the entire range.

The effect on $N O V U$ is shown in Fig. 5. Note that $r$ is not included as it does not effect $N O V U$. Over much of the $S O R$ range, each practice results in the same $N O V$ and thus the same $N O V U$. However, from SOR from 30 to $55 \%$ and above $90 \%$ the practices result in different $N O V U$ values. This can be used to select the practice that results in the most efficient vehicle use for an expected $S O R$ range. For example, if $S O R$ is expected to range from 45 to $55 \%$, one might select $H=10$ as the collection practice, as this results in the most efficient use of the collection vehicle over that range. Of course, one would have to evaluate the extra overtime costs associated with a $10 \mathrm{~h}$ workday.

The effect on $L R$ is shown in Fig. 6. Note that $r$ is not included in the figure as it has no effect on $L R$. The base condition is indicated by the horizontal line at 0 . Increasing $C_{\mathrm{p}}^{\mathrm{w}}$ from 5 to 6 working days produces a constant 2.1 collector-hours week $^{-1}$ increase over the entire range of $S O R$. This indicates that working 6 days per week will not reduce labor costs. Increasing $H$ to 10 or decreasing $N_{\mathrm{d}}$ to 1 both decrease $L R$. 


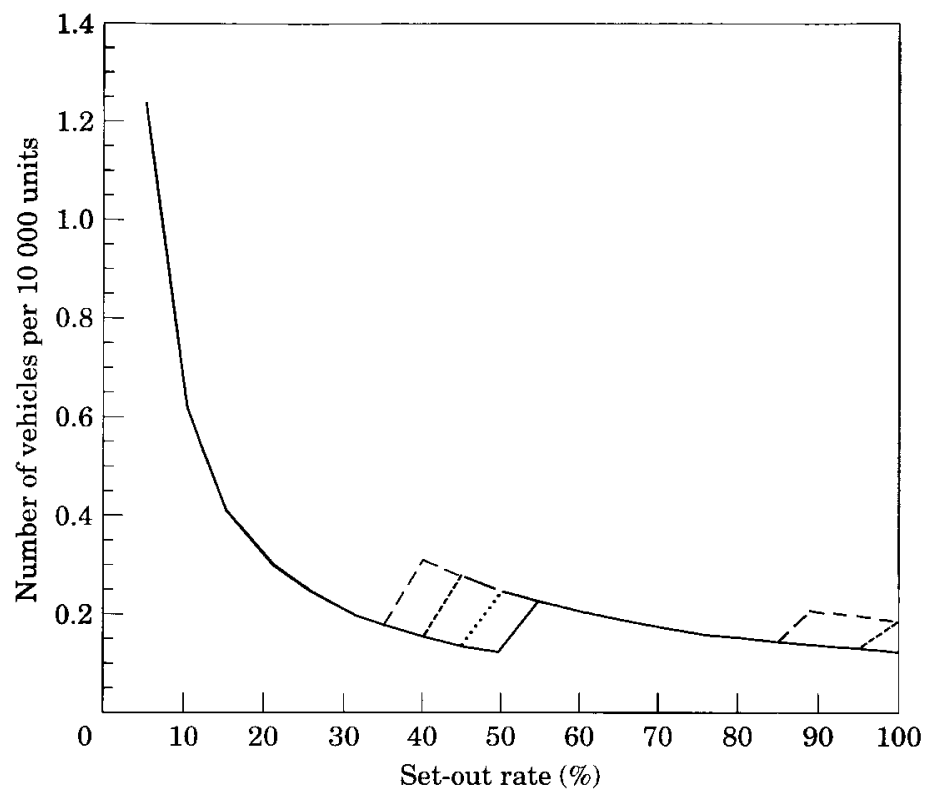

Fig. 5. Effect of collection practice on NOVU. (---), base condition; $\left(--, H=10 ;(-\cdots), N_{\mathrm{d}}=1 ;(\cdots)\right.$, workdays per collection period $=6$.

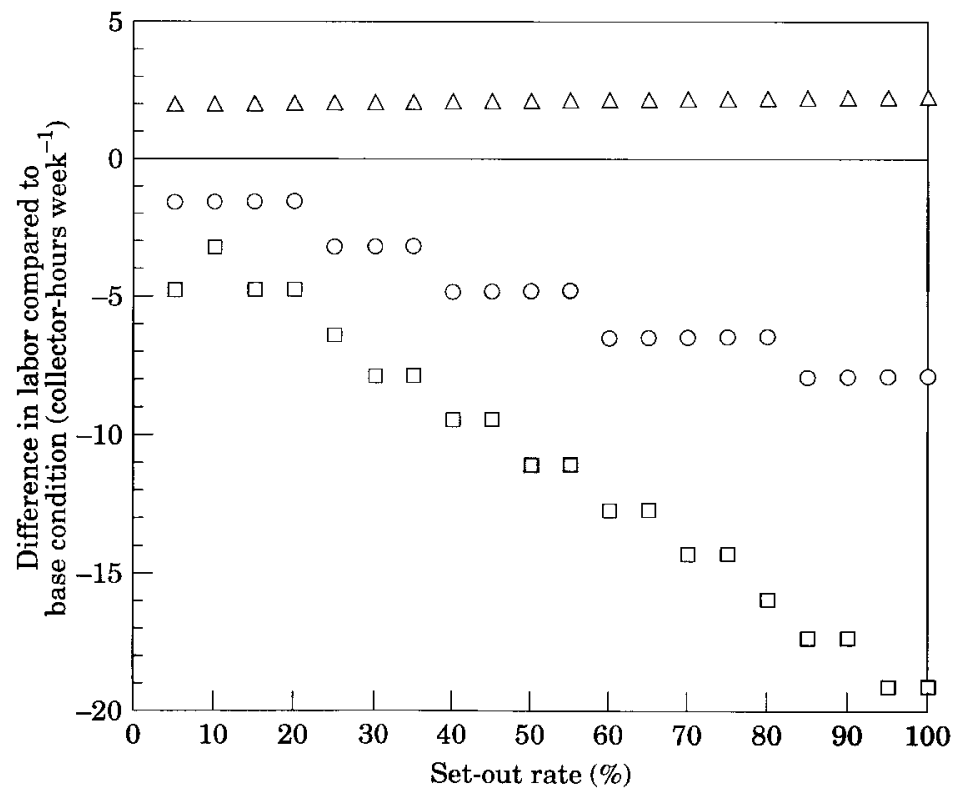

Fig. 6. Effect of collection practice on $L R .(\bigcirc), H=10 ; \square), N_{\mathrm{d}}=1 ;(\triangle)$, workdays per collection period $=6$.

However, the maximum decrease for $N_{\mathrm{d}}=1$ and SOR $=100 \%$-is less than 20 collectorhours week $^{-1}$, a reduction of less than $8 \%$. It appears that labor requirements are relatively insensitive to the variations in collection practice presented here. 
Selection of the appropriate collection practice must involve both feasibility and efficiency. Feasibility can be determined by checking the required truck volume, $v$, with the actual truck volume. Efficiency can be measured using the truck utilization factor (the fractional value of $N O V$ divided by the integer value of $N O V$ ) or the vehicles and labor requirements required per unit collected. The final decision concerning collection practice, however, must be based on feasibility, vehicle capital, maintenance and operating costs, and labor costs.

\section{Conclusions}

The conclusions and recommendations for future research are listed below:

(1) Methods for calculating route time, the required vehicle volume, number of vehicles, and labor requirements were presented and illustrated with a hypothetical example. The methods can be used to compare collection methods and determine program requirements.

(2) The methods presented in this paper can be used to estimate the effects of different collection method and practice. For example, variation of $v, H, N_{\mathrm{d}}$, and $C_{\mathrm{p}}^{\mathrm{w}}$ can change vehicle volume and number requirements, labor requirements, and vehicle and labor efficiency. This can aid the engineer or planner in designing new collection programs, or estimating the effect of modification.

(3) Future research should investigate the robustness of the simulation model and simple estimation procedure. For example, the model parameters estimated based on the data already gathered should be used to estimate times for the observed collection route on new collection days, i.e. route collection days not used in the determination of the model parameters, and new routes. The applicability of the equations over the $S O R$ range should be investigated. A data base of equation parameters should be developed for a universe of collection methods and route characteristics.

\section{References}

Everett, J. \& Shahi, S. (1996a) Curbside collection of yard waste: estimating route time (I). Journal of Environmental Engineering, ASCE, 122(1): 107-114.

Everett, J. \& Shahi, S. (1996b) Curbside collection of yard waste: simulation and case study (II). Journal of Environmental Engineering, ASCE, 122(1): 115-121.

Riley, P. \& Everett, J. (1995) Curbside collection of recyclable materials: time, vehicles, and labor. Air and Waste Management Association Annual Meeting. San Antonio, TX, U.S.A.

Tchobanoglous, G., Theisen, H. \& Vigil, S. (1993) Integrated Solid Waste Management: Engineering Principles and Management Issues. McGraw Hill: New York, U.S.A. 